The Egyptian Journal of Hospital Medicine (July 2019) Vol. 76 (3), Page 3684-3691

\title{
Strain Bull's Eye Plot Derived from 3D Speckle Tracking Imaging in Children with Dilated Cardiomyopathy
}

Enas Talaat Mansor Madkor*, Osama Abd Rab El-Rassoul Tolba, Waleed Ahmed El-Shehaby and Shaymaa Basuny El-Nemr

Department of Pediatric Medicine ${ }^{1}$, Faculty of Medicine, Tanta University, Egypt

*Corresponding author: Enas Talaat Mansor Madkor, Mobile: 01110219350; Email: enas_madkoor@yahoo.com

\begin{abstract}
Background: Cardiomyopathies (CMPs) are a group of myocardial diseases with adverse outcomes.

Aim of the study: Was to evaluate the global and segmental 3-dimensional strain using speckle tracking echocardiography in children with dilated cardiomyopathy and correlate this parameter with other echocardiographic findings especially 2-dimensional strain (2DS bull's eye).

Patients and Methods: 100 subjects were categorized into 2 groups: Group 1; 50 patients with dilated cardiomyopathy. Group 2; 50 healthy controls matched with the patient group. Echocardiographic studies were performed by the following: Routine echocardiographic examination, tissue Doppler examination (TDE): [systolic and diastolic mitral annulus velocities - LV myocardial performance Index (MPI)], speckling tracking technique [2D LV longitudinal strain (2DS bull's eye) - Auto EF for LV systolic function - sphericity index] and transthoracic 3DE examination (3DRTE) [3D longitudinal strain (3DS bull's eye)].

Results: There was a significant reduction in left ventricular ejection fraction (LVEF), sphericity index (SI), mitral annulus systolic velocity (S), early diastolic mitral annulus tissue velocity and late diastolic mitral annulus tissue velocity (E'/A') and LV GLS (global longitudinal strain) in patients when compared with controls but there was a significant increase in myocardial performance index (MPI) and 2 dimensional (2DS) than 3 dimensional (3DS) in patients when compared with controls. There was significant positive correlation between 2DS and 3DS GLS among patients also, there was good agreement between all items in 2DS and 3DS in patients group. Conclusion: The bull's eye plot offers an intuitive visual overview of LV myocardial function status in cardiomyopathies.
\end{abstract}

Keywords: Strain Bull's Eye Plot, 3D Speckle Tracking imaging, Dilated Cardiomyopathy.

\section{INTRODUCTION}

Cardiomyopathy (CMP) is defined as a disease of the myocardium linked to cardiac dysfunction. Understanding of CMP is very important, because it is related to heart failure in children and is the most common indicator for heart transplantation in children over one year old ${ }^{(1)}$.

Dilated Cardiomyopathy (DCM) is a myocardial disorder characterized by a dilated left ventricular (LV) chamber and systolic dysfunction which usually leads to congestive heart failure (CHF). In some patients, right ventricular dysfunction (RVD) is also noted and observed and may increase the severity of the clinical disease $^{(2)}$.

The newly developed 3D speckle tracking in real time 3D echocardiographic (RT3DE) datasets has the potential to circumvent these limitations because: (i) it does not depend on $2 \mathrm{D}$ views that can be foreshortened, and (ii) it tracks motion of speckles within the scan volume, irrespective of its direction. Three-dimensional (3D) STE has been shown to enable analysis of deformities in myocardium in its longitudinal, circumferential and radial direction in a single 3D volume set ${ }^{(3)}$. Three-dimensional strainrelay on sequences provides both quantitative and qualitative information regarding tissue motion and deformation ${ }^{(4)}$.

\section{AIM OF THE STUDY}

It was to evaluate the global and segmental 3dimensional strain using speckle tracking echocardiography in children with dilated cardiomyopathy and correlate this parameter with other echocardiographic findings especially 2-dimensional strain (2DS bull's eye).

\section{PATIENTS AND METHODS}

This observational case-control study was carried out during the period from April 2018 to January 2019 at Pediatric Cardiology Unit, Tanta University Hospital. It included 100 subjects who were classified into 2 groups. Group 1: 50 patients with primary dilated cardiomyopathy aged from 6 months up to 8 years, those patients attended the Cardiology Unit Pediatric department, Tanta University Hospital. Group 2: 50 healthy children matched for age and sex.

Inclusion criteria: Children less than 15 years with primary dilated cardiomyopathy.

Exclusion criteria: Children with congenital or acquired heart diseases other than dilated cardiomyopathy. Also; children with dilated cardiomyopathy secondary to systemic diseases were excluded. Written informed consent was obtained from 
the parents or guardians of the child.

The study was approved by the Ethics Committee of Faculty of Medicine, Tanta University.

Collection of data: All infants and children were subjected to:

1. Complete History Taking: Including personal, birth, developmental, feeding, and family history.

2. Thorough Clinical Examination: Including general, regional and systemic examination as body weight, height and vital signs; heart rate, blood pressure. Cardiac examination for detection of cardiomegaly and evidence of murmur was performed.

3. Investigations:

- Echocardiographic Examination.

1- Machine: Echocardiographic studies were performed using a commercially available ultrasound transducer and equipment (Vivid 7 or Vivid 9, GE Healthcare, Horten, Norway).

2- Transducers: Data acquisition was performed with a 3.5-MHz transducer, S7, and V3 matrix real-time 3 dimensional probes.

3- Workstation: Digital loops were stored on the hard disk of the echocardiography machine, and transferred to a workstation (Echo PAC PC, 112 and 113; GE, and Horten, Norway) for offline analysis.

- Echocardiographic technique:

1- Routine conventional echocardiographic examination:

2- Tissue Doppler Examination (TDE):

(A) Systolic and diastolic mitral annulus velocities (5).

(B) LV Myocardial Performance Index (MPI) ${ }^{(6)}$.

3- Speckling Tracking Technique:

(A) 2D LV Longitudinal Strain ${ }^{(7)}$ and Longitudinal strain bull's eye plot acquisition ${ }^{\left({ }^{(8)} \text {. }\right.}$

(B) Auto EF for LV systolic function ${ }^{(9)}$

(C) Sphericity Index ${ }^{(\boldsymbol{9})}$.

4- Transthoracic 3DE Examination (3DRTE): 3D Longitudinal Strain (3DS bull's eye) ${ }^{(\mathbf{1 0})}$.

\section{Statistical analysis}

In addition to the descriptive data, statistical analysis was done using IBM SPSS STATISTC VERSION 23 PROGRAM. Data were expressed as mean \pm SD and analyzed using the standard student "t test", test of significance of the difference between two means. The calculated " $\mathrm{t}$ " was compared with tabulated one at different levels of significance at the degree of freedom (df). P <0.05 was accepted as significant. Coefficient (r) of two variables was also done by using Pearson correlation coefficient ( $r$ ) with p-value Calculation.

\section{RESULTS}

Laboratory assessments of the measured parameters are presented in the following tables and figures:

Table (1): Comparison between patients and controls regarding age

\begin{tabular}{|c|c|c|c|c|}
\hline \multirow{2}{*}{ Groups } & \multicolumn{2}{|c|}{ Age (years) } & \multicolumn{2}{c|}{ T-test } \\
\cline { 2 - 4 } & Range & Mean \pm SD & T & P-value \\
\hline Patients & $0.5-8$ & $4.466 \pm 1.814$ & 1.679 & 0.090 \\
\hline Controls & $0.75-8$ & $3.633 \quad 2.024$ & & \\
\hline
\end{tabular}

Table (1) showed that there was no statistically significant difference was found between studied groups regarding age.

Table (2): Sex distribution in the studied groups

\begin{tabular}{|c|c|c|c|c|}
\hline \multicolumn{2}{|c|}{ Sex } & \multicolumn{3}{|c|}{ Groups } \\
\hline & & Patients & Controls & Total \\
\hline \multirow[t]{2}{*}{ Male } & $\mathbf{N}$ & 30 & 30 & 60 \\
\hline & $\%$ & 60 & 60 & 60.00 \\
\hline \multirow[t]{2}{*}{ Female } & $\mathbf{N}$ & 20 & 20 & 40 \\
\hline & $\%$ & 40 & 40 & 40.00 \\
\hline \multirow[t]{2}{*}{ Total } & $\mathbf{N}$ & 50 & 50 & 100 \\
\hline & $\%$ & 100.00 & 100.00 & 100.00 \\
\hline \multirow[t]{2}{*}{ Chi-Square } & $\mathrm{X}^{2}$ & \multicolumn{3}{|c|}{0.016} \\
\hline & P-value & \multicolumn{3}{|c|}{0.901} \\
\hline
\end{tabular}

Table (2) showed that there was no statistically significant difference was found between studied groups regarding sex.

Table (3): Comparison between patients and control as regards ejection fraction (EF) measured by auto EF 


\begin{tabular}{|c|c|c|c|c|}
\hline \multirow{2}{*}{ Groups } & \multicolumn{2}{|c|}{ LVEF(\%) } & \multicolumn{2}{c|}{ T-test } \\
\cline { 2 - 5 } & Range & Mean \pm SD & T & P-value \\
\hline Patients & $13-60$ & $\mathbf{4 3 . 3 6 0} \pm 11.760$ & $<0.001 *$ \\
\hline Controls & $60-70$ & 65.2347 .589 & & \\
\hline
\end{tabular}

Table (3) showed that the LVEF in Patients ranged from 13.0 - 60.0 with mean 43.360 \pm 11.760 . The LVEF in control ranged from $60.0-70.0$ with mean $65.234 \pm 7.589$. There was a statistically significant reduction in LVEF in patients when compared with controls. There was a significant reduction of EF in patients when compared with controls.

Table (4): Comparison between patients and control as regards sphericity index (SI) measured by 3DE

\begin{tabular}{|c|c|c|c|c|}
\hline \multirow{2}{*}{ Groups } & \multicolumn{2}{|c|}{ LV SI } & \multicolumn{2}{c|}{ T-test } \\
\cline { 2 - 4 } & Range & Mean \pm SD & T & P-value \\
\hline Patients & $0.11-1.63$ & $1.197 \pm 0.345$ & $<0.001 *$ \\
\hline Controls & $1.2-2.15$ & $1.566 \pm 0.272$ & & \\
\hline
\end{tabular}

P-value $<0.05=$ Significant

Table (4) showed that the SI in patient ranged from 0.11 to 1.63 with mean $1.197 \pm 0.345$, the SI in control group ranged from 1.2 to 2.15 with mean $1.566 \pm 0.272$, there was a statistically significant reduction in SI in patients when compared with controls.

Table (5): Comparison between patients and control as regards (Mitral Annulus systolic velocity) measured by Tissue Doppler examination (TDI)

\begin{tabular}{|c|c|c|c|c|}
\hline \multirow{2}{*}{ Group } & \multicolumn{2}{|c|}{ S(cm/second) } & \multicolumn{2}{|c|}{ T-test } \\
\cline { 2 - 5 } & Range & Mean \pm SD & T & P-value \\
\hline Patients & $2-6$ & $\mathbf{3 . 6 6 7} \pm 1.061$ & 13.554 & $<0.001^{*}$ \\
\hline Control & $6-8$ & $6.933 \pm 0.785$ & & \\
\hline
\end{tabular}

S: Mitral Annulus systolic velocity.

Table (5) showed that the $S$ in studied group ranged from 2 to $6 \mathrm{~cm} / \mathrm{sec}$ with mean $3.667 \pm 1.061$, The $S$ in control group ranged from 6 to $8 \mathrm{~cm} / \mathrm{sec}$. with mean $6.933 \pm 0.785$. There was a significant reduction of mitral annulus systolic velocity in patients when compared with controls.

Table (6): Comparison between patients and control as regards ( $E^{\prime} / A^{\prime}$ ratio) measured by Tissue Doppler Imaging (TDI).

\begin{tabular}{|l|c|c|c|c|}
\hline \multirow{2}{*}{ Group } & \multicolumn{2}{|c|}{ E'$^{\prime} / \mathbf{A}^{\prime}$} & \multicolumn{2}{|c|}{ T-test } \\
\cline { 2 - 5 } & Range & Mean \pm SD & T & P-value \\
\hline Patients & $0.6-1.8$ & $1.147 \pm 0.401$ & 4.584 & $<0.001^{*}$ \\
\hline Controls & $1.1-1.9$ & $1.540 \pm 0.246$ & & \\
\hline
\end{tabular}

E'=Early diastolic mitral annulus tissue velocity and $\mathrm{A}^{\prime}=$ Late diastolic mitral annulus tissue velocity.

Table (6): Shows comparison of mean value of E'/A' in relation to studied group:

- The E'/A' in studied group ranged from 0.6 to 1.8 with mean $1.147 \pm 0.401$,

- The E'/A' in control group ranged from 1.1 to 1.9 with mean $1.540 \pm 0.246$,

- There was a significant reduction of (E'/A' ratio) in patients when compared with controls.

Table (7): Comparison between patients and control as regards LV Myocardial Performance Index (MPI) measured by Tissue Doppler Imaging (TDI). 


\begin{tabular}{|c|c|c|c|c|}
\hline \multirow{2}{*}{ Groups } & MPI & \multicolumn{2}{|c|}{ T-test } \\
\cline { 2 - 4 } & Range & Mean \pm SD & T & P-value \\
\hline Patients & $1.57-2.64$ & $\mathbf{1 . 8 7 6} \pm 0.233$ & 32.793 & $<0.001 *$ \\
\hline Control & $0.3-0.5$ & $0.407 \pm 0.078$ & & \\
\hline
\end{tabular}

MPI: myocardial performance index.

Table (7) shows comparison of mean value of MPI in relation to studied group:

- The MPI of the studied group ranged from 1.57 to 2.64 with mean $1.876 \pm 0.233$

- The MPI of the control group ranged from 0.3 to 0.5 with mean $0.407 \pm 0.078$

- There was a significant increase in LV Myocardial Performance Index in patients when compared with controls.

Table (8): Comparison between patients and control as regard LV GLS (LV Global Longitudinal strain) measured by 2 D STE

\begin{tabular}{|c|c|c|c|c|}
\hline \multirow{2}{*}{ Groups } & \multicolumn{2}{|c|}{ LV GLS (\%) } & \multicolumn{2}{|c|}{ T-test } \\
\cline { 2 - 4 } & Range & Mean \pm SD & T & P-value \\
\hline Patients & $(-5)-(-23)$ & $\mathbf{- 1 2 . 6 6 7} \pm 4.943$ & 12.361 & $<\mathbf{0 . 0 0 1 *}$ \\
\hline Controls & $(-22)-(-27)$ & $-24.400 \pm 1.610$ & & \\
\hline
\end{tabular}

LV GLSS: left ventricular global longitudinal strain.

Table (8) showed that the LV GLS of the studied group ranged from -5 to -23 with mean $-12.667 \pm 4.943$, The GLSS of the control group ranged from -22 to -27 with mean $-24.400 \pm 1.610$, There was significant reduction of LV global longitudinal systolic strain in patients when compared with controls.

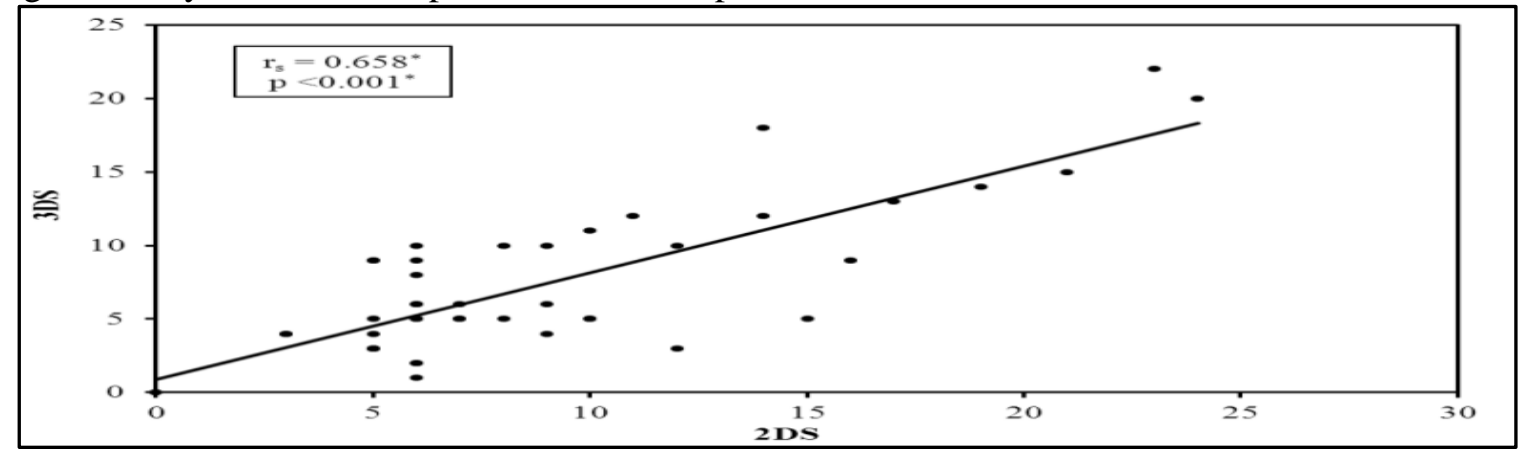

Figure (1): Correlation between 2DS and 3DS in patients group.

Figure (1) showed that here was statistically significant positive correlation between 2DS and 3DS among cases with $\mathrm{p}$ value $=<0.001$.

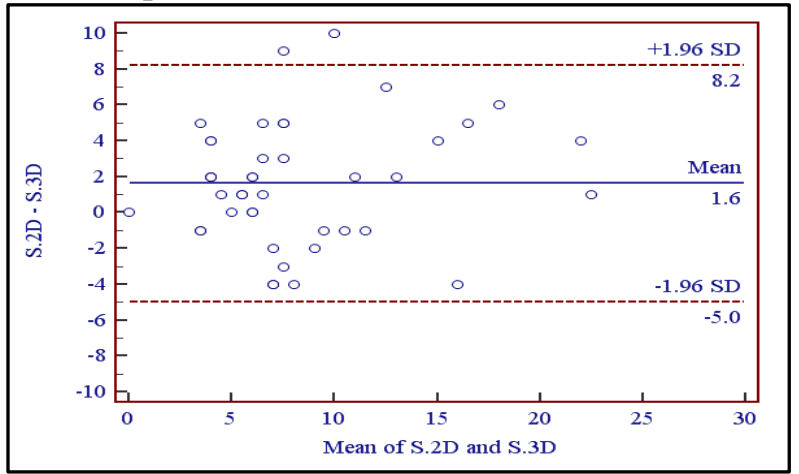

Figure (2): Agreement between 2DS and 3DS in patients group.p $=0.003^{*}$ (Fixed Bias)

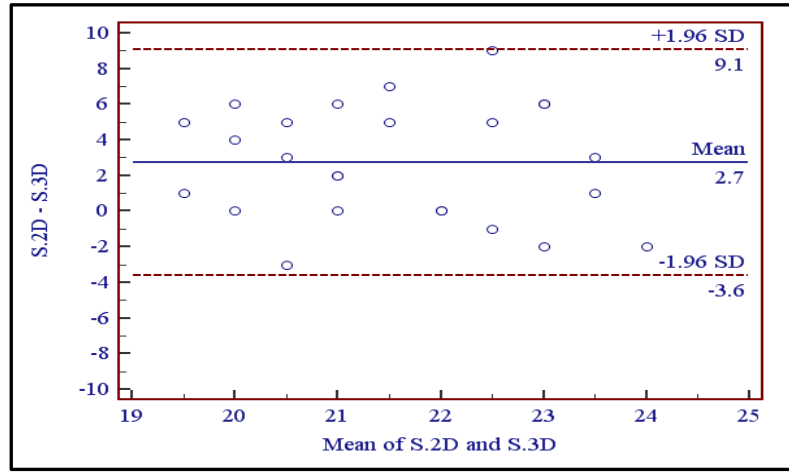

Figure (3): Agreement between 2DS and 3DS in patients group.p $<0.001^{*}$ (Fixed Bias)

Figure $(\mathbf{2}, \mathbf{3})$ showed that there was an agreement between 2DS and 3DS in patients group.

Table (9): Comparison between 2D and 3D GLS in each group 


\begin{tabular}{|c|c|c|c|c|c|}
\hline & 2DS GLS & 3DS GLS & Mean difference & $\mathbf{t}(\mathbf{p})$ & $\mathbf{r}(\mathbf{p})$ \\
\hline \multicolumn{6}{|l|}{ Patients } \\
\hline Min. - Max. & $(-5.0)-(-23.0)$ & $(-0.30)-(-22.0)$ & \multirow[t]{3}{*}{$1.63 \pm 3.37$} & \multirow[t]{3}{*}{$3.164^{*}\left(<0.003^{*}\right)$} & \multirow[t]{3}{*}{$0.796^{*}\left(<0.001^{*}\right)$} \\
\hline Mean \pm SD & $-12.66 \pm 4.94$ & $-7.51 \pm 4.99$ & & & \\
\hline Median & -7.50 & -6.0 & & & \\
\hline \multicolumn{6}{|l|}{ Control } \\
\hline Min. - Max. & $(-22)-(-27)$ & $-17.0-25.0$ & \multirow[t]{3}{*}{$2.72 \pm 3.23$} & \multirow[t]{3}{*}{$4.205^{*}\left(<0.001^{*}\right)$} & \multirow[t]{3}{*}{$-0.186(0.374)$} \\
\hline Mean \pm SD & $-24.92 \pm 2.0$ & $-20.20 \pm 2.20$ & & & \\
\hline Median & -22.0 & -20.0 & & & \\
\hline
\end{tabular}

t: Paired t-test for comparing between the two techniques (if significant there is a difference), r: Pearson coefficient, *: Statistically significant at $\mathrm{p} \leq 0.05$ GLS=Global Longitudinal Strain

Table (9) showed the following:

- The 2DS in Patients ranged from -5.0 to -23 with mean $-12.66 \pm 4.94$, 3DS in Patients ranged from -0.30 to -22 with mean $-7.51 \pm 4.99$ There was a statistically significant increase in 2DS than 3DS among cases.

- The 2DS in control group ranged from -22 to -27 with mean $-24.92 \pm 2.0$. The 3DS in control group ranged from 17 to -25 with mean $20.20 \pm 2.20$, There was a statistically significant increase in 2DS than 3DS among cases among control.

Table (10): Correlation coefficients of segmental 2D and 3D LS

\begin{tabular}{|l|c|c|c|}
\hline \multicolumn{1}{|c|}{ 2D vs 3D SLSo } & r & $\mathbf{p}$ & ICC (95\% CI) \\
\hline Basal Ant & 0.101 & 0.681 & $0.097(-0.352-0.515)$ \\
\hline Basal anti post. & -0.042 & 0.887 & $-0.041(-0.608-0.504)$ \\
\hline Basal infro. Post. & 0.263 & 0.324 & $0.216(-0.325-0.638)$ \\
\hline Basal infer. & 0.295 & 0.220 & $0.300(-0.178-0.659)$ \\
\hline Basal Info lat. & 0.378 & 0.100 & $0.302(-0.078-0.631)$ \\
\hline Basal ant. Lat. & 0.009 & 0.970 & $0.009(-0.394-0.433)$ \\
\hline Mid ant. & -0.008 & 0.971 & $-0.009(-0.448-0.417)$ \\
\hline Mid. Ant. 6 SEBT. & 0.186 & 0.432 & $0.180(-0.298-0.576)$ \\
\hline Med inf. Sep. & $0.701^{*}$ & $0.001^{*}$ & $0.704(0.395-0.871)$ \\
\hline Med inf. & 0.327 & 0.254 & $0.318(-0.214-0.712)$ \\
\hline Med inf. Lat. & 0.331 & 0.179 & $0.294(-0.213-0.666)$ \\
\hline Med ant. Lat. & 0.045 & 0.854 & $0.046(-0.428-0.488)$ \\
\hline Apical ant. & 0.029 & 0.907 & $0.018(-0.292-0.394)$ \\
\hline Apical sept. & -0.176 & 0.432 & $-0.091(-0.387-0.279)$ \\
\hline Apical in. & $0.499^{*}$ & $0.025^{*}$ & $0.371(-0.086-0.695)$ \\
\hline Apical lat. & -0.178 & 0.493 & $-0.124(-0.531-0.351)$ \\
\hline Apex & -0.141 & 0.577 & $-0.044(-0.429-0.393)$ \\
\hline
\end{tabular}

r: Pearson coefficient $*$ : Statistically significant at $\mathrm{p} \leq 0.05 \mathrm{ICC}$ :Interclass CorrelationCI: Confidence interval SLS=Segmental Longitudinal Strain.

Table (10) showed that the ICCs were classified using a system suggested by McGraw and Wong 11 as follows: (1) less than $0.75 \mathrm{Z}$ poor agreement; 0.75 to less than $0.90 \mathrm{Z}$ moderate agreement; (3) 0.90 or greater $\mathrm{Z}$ high agreement. $P$ value less than 0.05 was considered statistically significant. 


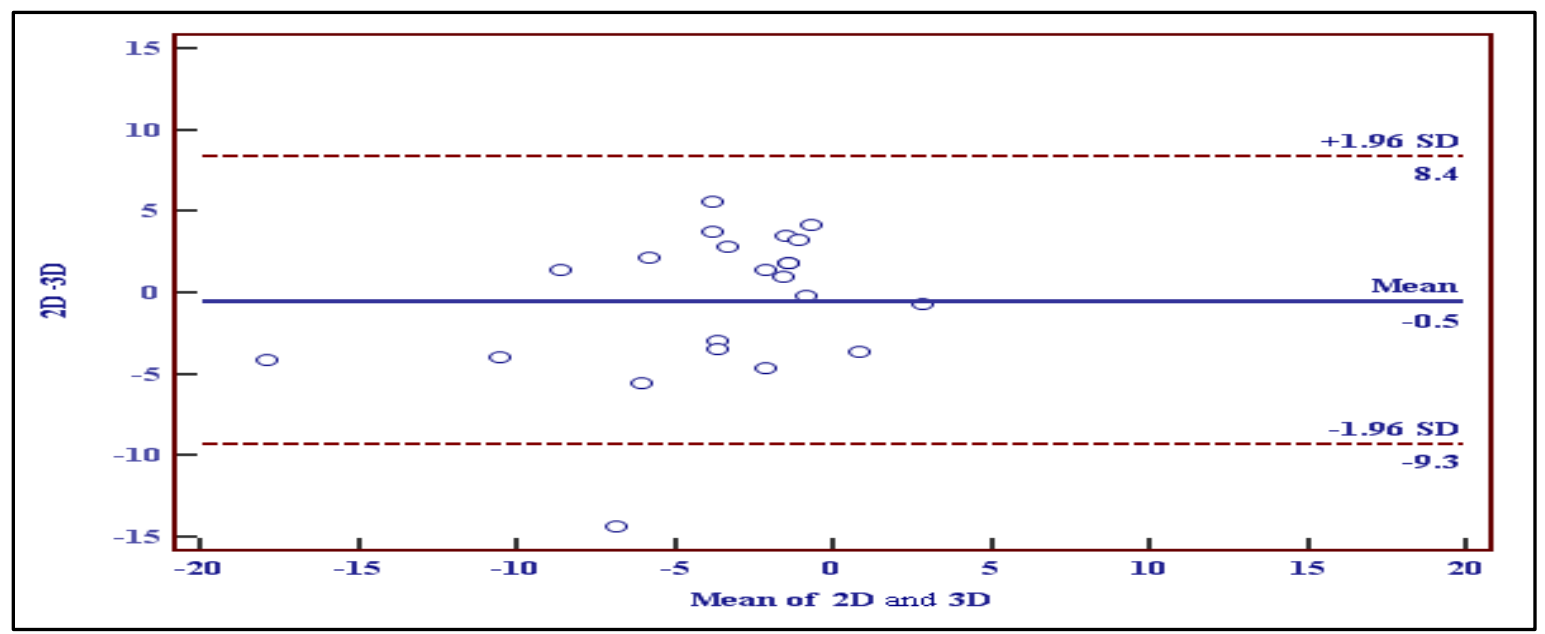

Figure (4): Agreement between 2DS and 3D GLS in patients group(global longitudinal strain)

Figure (4) showed that there was good agreement between all items between 2DS and 3DS (global longitudinal strain)

\section{DISCUSSION}

Assessing the size and functions of the heart is an integral part of evaluation of cardiac status. For assessing the cardiac functions, M-mode, 2D imaging and Doppler methods can be used to assess the functions of ventricles ${ }^{(11)}$.

A complete 3D echocardiographic study includes assessment of ventricular function, morphology of valves, and hemodynamic status. Unlike 2D echocardiography, where standard views are described depending on the plane through which they pass, 3D echocardiography is inherently volumetric. As such, it allows both an external view of the heart and multiple internal perspectives (through cropping) ${ }^{(\mathbf{1 2})}$.

The hallmark of the disease is LV dilatation and/or dysfunction. Dilatation may precede dysfunction in many patients and therefore attention to accurate chamber dimensions, indexed according to the surface area of the bodyis important. This is of particular relevance in the long-term follow-up of DCM patients, in order to evaluate disease progression or response to treatments ${ }^{(13)}$.

The work was conducted on 100 children (50 patients who suffered from primary dilated cardiomyopathy and 50 healthy children as a control group). The age of patients ranged from 6 months up to 8 years, with mean $4.466 \pm 1.814$ years. There was no significant difference between patients and controls as regard to age and sex. The male distribution was more among dilated cardiomyopathy 27 (54\%). The present study is in agreement with Hershberger et al. ${ }^{(14)}$, it agrees also with Towbin et al. ${ }^{(15)}$ and Cox et al. ${ }^{(16)}$ who explained that boys have a higher DCM incidence than girls, related to $\mathrm{X}$-linked genetic causes.

In the current study SI in patients was measured using speckling tracking technique and was ranged from 0.11 to 1.63 with mean $1.197 \pm 0.345$, The SI in control group was ranged from 1.2 to 2.15 with mean $1.5666 \pm 0.272$, There was a statistically significant reduction in SI in patients when compared with controls.

The sphericity index (SI) is the ratio between the short diameter (mid-cavity level in the short axis view) and the long diameter (length between the mitral annulus to apex in the apical view) and this ratio predicts the remolding of LV and functional capacity in patients with LV dysfunction ${ }^{(17)}$.

Van Dalen et al. ${ }^{(18)}$ found that, that LV sphericity index was the strongest independent predictor of basal and apical LV peak systolic rotation (Rot $\left.{ }_{\max }\right)$ and instantaneous LV peak systolic twist (Twist max). LV apical rotation and twist are significantly influenced by LV configuration.

The current study showed that, the mitral annulus systolic velocity(S) assisted by tissue Doppler in patients was ranged from 2 to $6 \mathrm{~cm} / \mathrm{s}$ with mean 3.667 \pm 1.061 , the $\mathrm{S}$ in control group was ranged from 6 to 8 $\mathrm{cm} / \mathrm{s}$ with mean $6.933 \pm 0.785$. There was a statistically significant reduction in $S$ in patients when compared with controls. This agrees with previous studies Abduch et al.$^{(19)}$ who found (S) was significantly lower in the DCM group compared to controls group.

The present study was supported by previous data as Abduch et al. ${ }^{(19)}$, Yu et al. ${ }^{(20)}$, McMahon $\boldsymbol{e t}$ al. ${ }^{(21)}$, Zamorano and Lennie ${ }^{(22)}$, and Mohammed and Friedberg ${ }^{(23)}$ who confirmed usefulness for measuring the $S^{\prime}$ as a tool for assessment of systolic function.

The current study showed that, The E'/A' ratio assisted by tissue Doppler in patients was ranged from. 0.6 to 1.8 with mean $1.147 \pm 0.401$, The E'/A' in control 
group ranged from 1.1 to 1.9 with mean $1.540 \pm 0.246$. There was a statistically significant reduction in $E^{\prime} / A^{\prime}$ in patients $\mathrm{s}$ when compared with controls. These data confirm the diastolic dysfunction in dilated cardiomyopathy patients with impaired LV filling. Similar findings were reported by Mark et $\boldsymbol{a l} .{ }^{(24)}$.The current study is in contrast with Abduch et al. ${ }^{\left({ }^{(19)}\right.}$ who found that, $\mathrm{E}^{\prime} / \mathrm{A}^{\prime}$ ratio was higher in the DCM group compared with controls. The explanation of this discrepancy that the patients of that study may be advanced patients and suffering from restrictive filling during diastole.

The present study showed that the Myocardial Performance Index (MPI) assisted by tissue Doppler in patients was ranged from 1.57 to 2.64 with mean 1.876 \pm 0.233 . The MPI in control was ranged from 0.3 to 0.5 with mean $0.407 \pm 0.078$, there was a statistically significant increase in MPI in patients when compared with controls. The current study agrees with previous reports as Abduch et al. ${ }^{(19)}$ and McMahon et al. ${ }^{(21)}$. This could be explained due to LV systolic and diastolic dysfunction that reported in our patients, as the MPI reflects both systolic and diastolic function of the ventricles.

The present study showed that the Left ventricular ejection fraction (LVEF) assisted by speckling tracking (auto $\mathrm{EF}$ ) in patients was ranged from $13-60 \%$ with mean $43.360 \pm 11.760$, the LVEF in control ranged from $60-70 \%$ with mean $65.234 \pm$ 7.589 , there was a statistically significant reduction in LVEF in patients when compared with controls. This agrees with Elkilary et al. ${ }^{(2)}$, Abduch et al. ${ }^{(19)}$, Koestenberger et al. ${ }^{(25)}$, Bergenzaun ${ }^{(26)}$ and Taşolar et al. ${ }^{(27)}$ who found that LVEF was lower in the DCM group compared to controls group.

This study showed that, the 2DS in patients was ranged from -5 to $-23 \%$ with mean $-12.66 \pm 4.94$. 3DS in patients was ranged from -3 to -22 with mean -7.51 \pm 4.99 , the $2 \mathrm{DS}$ in control group was ranged from -22 to -27 with mean $-24.92 \pm 2.0$, the $3 \mathrm{DS}$ in control group ranged from -17 to -25 with mean- $20.20 \pm 2.20$.

There was significant reduction of LV global longitudinal systolic strain in patients when compared with controls as regard to both 2DS and 3DS. There was a statistically significant increase in 2DS than 3DS among patients. However, there was statistically significant positive correlation between 2DS and 3DS among patients. There was also a good agreement between 2DS and 3D segmental and global longitudinal strain.

This agrees with Trache $\boldsymbol{e t}$ al. ${ }^{(28)}$ who found that, there was statistically significant positive correlation between 2DS and 3DS. They alsomade comparison of $3 \mathrm{D}$ and $2 \mathrm{D}$ speckle tracking performed on standard 2D and triplane 2D datasets of normal and pathological left ventricular (LV) wall-motion patterns with a focus on the effect that 3D volume rate (3DVR), image quality and tracking artifacts have on the agreement between $2 \mathrm{D}$ and $3 \mathrm{D}$ speckle tracking. 37 patients with normal LV function and 18 patients with ischemic wall-motion abnormalities underwent $2 \mathrm{D}$ and 3D echo-cardiography, followed by offline speckle tracking measurements. The values of 3D global, regional and segmental strain were compared with the standard 2D strain values.

The comparative analysis of 2D and 3D GLS values showed very good correlation coefficients between standard/triplane 2D and 3D GLS. Nevertheless, a systematic bias was observed between the 2D and 3D measurements, which was also documented by Reant et al. ${ }^{(29)}$ that the 3D GLS values were systematically lower than the 2D GLS values, with differences reaching statistical significance. This effect was explained as an effect of out-of-plane speckle patterns, as well as technical differences between the two methods.

\section{CONCLUSION}

The bull's eye plot offers an intuitive visual overview of the global and regional LV myocardial function status in cardiomyopathies. Although the bull's eye plot could provide additional important information in patients with cardiomyopathies with $\mathrm{LVH}$, a comprehensive cardiac workup remains essential to confirm the diagnosis of cardiomyopathies, including the evaluation of family and clinical history, non-cardiac involvements assessment, laboratory and eventually genetic tests, ECG, and multi-modality cardiac imaging (echocardiography, CMRI).

\section{REFERENCES}

1. Bakeet M, Mohamed M, Allam A et al. (2016): Childhood Cardiomyopathies: A Study in Tertiary Care Hospital in Upper Egypt. Electronic Physician, 8(11):31643169.

2. Elkilany N, Galal E, Mustafa A et al. (2008): Dilated Cardiomyopathy in Children and Adults: What is New? The Scientific World Journal, 8: 762-775.

3. Badano L, Cucchini U and Muraru D (2013): Use of three dimensional speckle tracking to assess left ventricular myocardial mechanics: inter-vendor consistency and reproducibility of strain measurements. Eur Heart J Cardiovasc Imaging, 14: 285-293.

4. Pedrizzetti G, Claus P, Kilner P et al. (2016): Principles of cardiovascular magnetic resonance feature tracking and echocardiographic speckle tracking for informed clinical use. J Cardiovasc Magn Reson., 18(1):1-12.

5. Yu C, Gorcsan J, Bleeker Get al. (2007): Usefulness of tissue Doppler velocity and strain dys-synchrony for predicting left ventricular reverse remodeling response after 
cardiac resynchronization therapy. The American Journal of Cardiology, 100(8):1263-1270.

6. Williams R, Ritter S, Tani L et al. (2000): Quantitative assessment of ventricular function in children with single ventricles using the Doppler myocardial performanceindex. The American Journal of Cardiology, 86(10): 1106-1110.

7. Scherptong R, Mollema S, Blom $\mathbf{N}$ et al. (2009):Right ventricular peak systolic longitudinal strain is a sensitive marker for right ventricular deterioration in adult patients with tetralogy of Fallot. The International Journal of Cardio-vascular Imaging, 25(7):669-676.

8. Voigt J, Pedrizzetti G, Lysyansky Pet al. (2015): Definitions for a common standard for 2D speckle tracking echocardiography: consensus document of the EACVI/ASE/Industry Task Force to standardize deformation imaging. Eur Heart $\mathbf{J}$ Cardiovasc Imaging, 16(1):1-11.

9. Sivesgaard $K$, Christensen $S$, Nygaard $H$ et al. (2009).Speckle tracking ultrasound is independent of insonation angle and gain: an in vitro investigation of agreement with sonomicrometry. Journal of the American Society of Echocardiography, 22(7): 852-858.

10.Gayat E, Ahmad H, Weinert $L$ et al. (2011): Reproducibility and inter-vendor variability of left ventricular deformation measurements by threedimensional speckle-tracking echo-cardiography. J Am SocEchocardiogr., 24:878-85.

11.Sanbe A (2013): Dilated cardiomyopathy:a disease of the myocardium. Biological\& Pharmaceutical Bulletin, 36: 1822.

12.Hung J, Lang R, Flachskampf $\mathbf{F}$ et al. (2007): $3 \mathrm{D}$ echocardiography: a review of the current status and future directions. J Am SocEchocardiogr., 20(3):213-33.

13.Egan $M$ andIonescu A (2008): The pocket echocardiograph: a useful new tool? Eur J Echocardiogr., 9: 721-725.

14. Hershberger R, Givertz M, Ho C et al. (2018): Genetic evaluation of cardiomyopathy - a heart failure society of america practice guideline. Journal of Cardiac Failure, 24:281-302.

15. Towbin JA, Lowe AM, Colan SD et al. (2006): Incidence, causes, and outcomes of dilated cardiomyopathy in children. JAMA., 296:1867-1876.

16. Cox G, Sleeper L, Lowe A et al. (2006): Actors associated with establishing a causal diagnosis for children with cardiomyopathy. Pediatrics, 118:1519-31.

17. Choi J and Sung J (2009):Left Ventricular Sphericity Index in Asymptomatic Population. JCU., 17(2):54-59.
18. Van Dalen B, Kauer F, Vletter W et al. (2010):Influence of cardiac shape on left ventricular twist. J ApplPhysiol., 108(1):146-51.

19. Abduch M, Salgo I, Tsang W et al. (2012): Myocardial deformation by speckle tracking in severe dilated cardiomyopathy. Arq Bras Cardiol., 99:834-43.

20. Yu C, Lin H, Yang H et al. (2002): Progression of systolic abnormalities in patients with - isolated\| diastolic heart failure and diastolic dysfunction. Circulation, 105(10): 1195- 1201.

21. McMahon C, Nagueh S, Eapen $R$ et al. (2004): Echocardiographic predictors of adverse clinical events in children with dilated cardiomyopathy: a prospective clinical study. Heart, 90: 908-915.

22.Zamorano J andLennie V (2006): Clinical applications of tissue Doppler Rev Port Cardiol., 25(9):797-798.

23. Mohammed A and Friedberg $M$ (2008): Feasibility of a new tissue Doppler based method for comprehensive evaluation of left ventricular intra-ventricular mechanical dyssynchrony in children with dilated cardiomyopathy. J Am SocEchocardiogr., 21:1062-7.

24. Mark K, Susan L, Arshiya F et al.(2008): Left Ventricular Diastolic Mechanical Dyssynchronyand Associated Clinical Outcomes in Children With Dilated Cardiomyopathy. CircCardiovasc Imaging, 1:50-57.

25. Koestenberger $M$, Friedberg $M$, Ravekes $W$ et al. (2012): Noninvasive imaging for congenital heart disease: recent innovations in transthoracic echocardiography. J ClinExpCardiolog., 8(2): 1-33.

26. Bergenzaun L, Öhlin H, Gudmundsson P et al. (2013): Mitral

annular plane systolic excursion (MAPSE) in shock: a valuable echocardiographic parameter in intensive care patients. Cardiovasc Ultrasound, 11(16):1-8.

27. Taşolar H, Mete T, Çetin M et al. (2014): Mitral annular plane

systolic excursion in the assessment of left ventricular diastolic dysfunction in obese adults. Anatol J Cardiol., 15 (7): 558-64.

28. Trache, T, Stöbe, S, Tarr, A et al.(2014).The agreement between 3D, standard 2D and triplane 2D speckle tracking: effects of image quality and 3D volume rate. Echo research and practice, 1(2):71-83.

29. Reant P, Barbot L, Touche Cet al. (2012): Evaluation of global left ventricular systolic function using threedimensional echocardiography speckle-tracking strain parameters Journal of the American Society of Echo-cardiography, 25: 68-79. 